\title{
Habitat distribution of dipterocarp species in the Leyte Cordillera: an indicator for species - site suitability in local reforestation programs
}

\author{
Gerhard LANGENBERGER*
}

Institute of Plant Production and Agroecology in the Tropics and Subtropics (380b), University of Hohenheim, 70593 Stuttgart, Germany

(Received 17 January 2005; accepted 6 July 2005)

\begin{abstract}
Dipterocarpaceae is the most important family of economic trees in southeast Asia. In the Philippines, most dipterocarp forests have vanished due to logging, shifting cultivation and transformation into settlements or agricultural fields. With an increasing interest for native tree species in land rehabilitation and reforestation, the need to identify the still available species resources as well as their habitat preferences arises. I analysed vegetation data from the Leyte Cordillera on the island of Leyte, Philippines, to document the occurrence and habitat distribution of dipterocarp species. A total of 18 species belonging to the six Philippine dipterocarp genera and representing all eight Philippine dipterocarp timber groups were encountered. Distinct habitat distribution patterns and elevational ranges could be observed, that could serve as baseline information for ensuring species-site suitability in local reforestation and tree plantation programs.
\end{abstract}

Dipterocarpaceae / land rehabilitation / native species / Philippines / reforestation

\begin{abstract}
Résumé - Distribution écologique des espèces de Dipterocarpaceae dans la Cordillère de Leyte (Philippines) : un guide pour le choix d'espèces bien adaptées aux conditions du milieu dans les projets locaux de reboisement. Les Dipterocarpaceae représentent la famille la plus importante d'arbres d'intérêt économique en Asie du Sud-Est. Aux Philippines, la plupart des forêts à Dipterocarpaceae ont disparu sous les effets conjugués de l'exploitation forestière, de l'agriculture « itinérante » et de l'augmentation des surfaces agricoles et des zones habitées. L'intérêt croissant pour l'utilisation d'espèces indigènes dans les programmes de reboisement rend de plus en plus nécessaire l'identification des ressources en espèces indigènes et la caractérisation de leurs amplitudes écologiques. Dans cette étude, j'ai analysé des données sur la végétation de la Cordillère de Leyte (île de Leyte, Philippines), pour documenter la fréquence d'apparition et la répartition écologique des espèces de Dipterocarpaceae et pour préciser les habitats préférentiels de ces espèces. Au total, 18 espèces ont été recensées représentant les six genres et les huit groupes de bois associés aux Diptérocarpaceae rencontrés aux Philippines. Ces espèces présentent des habitats bien distincts liés, entre autre, aux tranches altitudinales. Ces informations pourront servir de guide pour le choix d'espèces bien adaptées à leur milieu dans les projets locaux de boisement et de reboisement.
\end{abstract}

Dipterocarpaceae / restauration des sols / espèce indigène / Philippines / reboisement / exigences écologiques

\section{INTRODUCTION}

The Dipterocarpaceae are the most important source of timber in Southeast Asia [19]. This was especially true for the Philippines, which was famous for the dominance of this family in its lowland forests, where dipterocarps contributed $94 \%$ of the timber volume [19]. Nowadays, only few remnants of dipterocarp forests are left in the Philippine archipelago. As of 1999, the forest cover of the Philippines was estimated at $18.3 \%$ of total land area, and the extent of primary forest at $2.7 \%$ [9]. Many formerly forested areas have been logged and transformed into permanent agricultural land and settlements [9]. Additionally, large tracts of logged-over forests and shifting cultivation areas developed into economically unproductive grassland due to inappropriate land use practices. Dipterocarp forest remnants are now generally found in localities where large-scale logging was not profitable and where access was hampered by the difficult terrain as in rugged and mountainous areas. The island of Leyte provides a typical example of this situation. Forty percent of its land surface is covered by grassland and barren land, another $40 \%$ by coconut plantations [6]. Only $2 \%$ of the island is still covered by primary forest [5].

Despite their predominant role in forest exploitation dipterocarps have never played a significant role in reforestation or land rehabilitation. Instead, exotic tree species have long been - and still often are - the preferred choice [7]. The use of native tree species however receives increasing attention $[4,8,14]$, but in practice, such use is hampered by the fragmentary ecological knowledge of native species - including dipterocarps.

The objective of this paper is therefore to promote the successful and sustainable application of this important native timber group by documenting the locally still available species resources of this family as well as their distribution and habitat preferences.

\footnotetext{
* Corresponding author: langenbe@uni-hohenheim.de
} 
Table I. Distribution of the sampling plots among topographic habitats and elevation classes.

\begin{tabular}{|c|c|c|c|c|c|c|}
\hline \multirow{2}{*}{ m a.s.1. } & \multicolumn{4}{|c|}{ Pananawan plots } & \multirow{2}{*}{$\begin{array}{l}\text { Happy Valley plots } \\
\text { Undulating plateau }\end{array}$} & \multirow{2}{*}{ Total } \\
\hline & Ridge & Upper slope & Middle slope & Lower slope & & \\
\hline $50-150$ & & & & - & & \\
\hline$>150-250$ & 1 & & 1 & 2 & & 4 \\
\hline$>250-350$ & 4 & & 2 & 1 & & 7 \\
\hline$>350-450$ & 2 & 2 & 4 & 3 & & 11 \\
\hline$>450-550$ & 8 & 4 & 2 & & & 14 \\
\hline$\sim 650-700$ & & & & & 21 & 21 \\
\hline Total & 15 & 6 & 9 & 6 & 21 & 57 \\
\hline
\end{tabular}

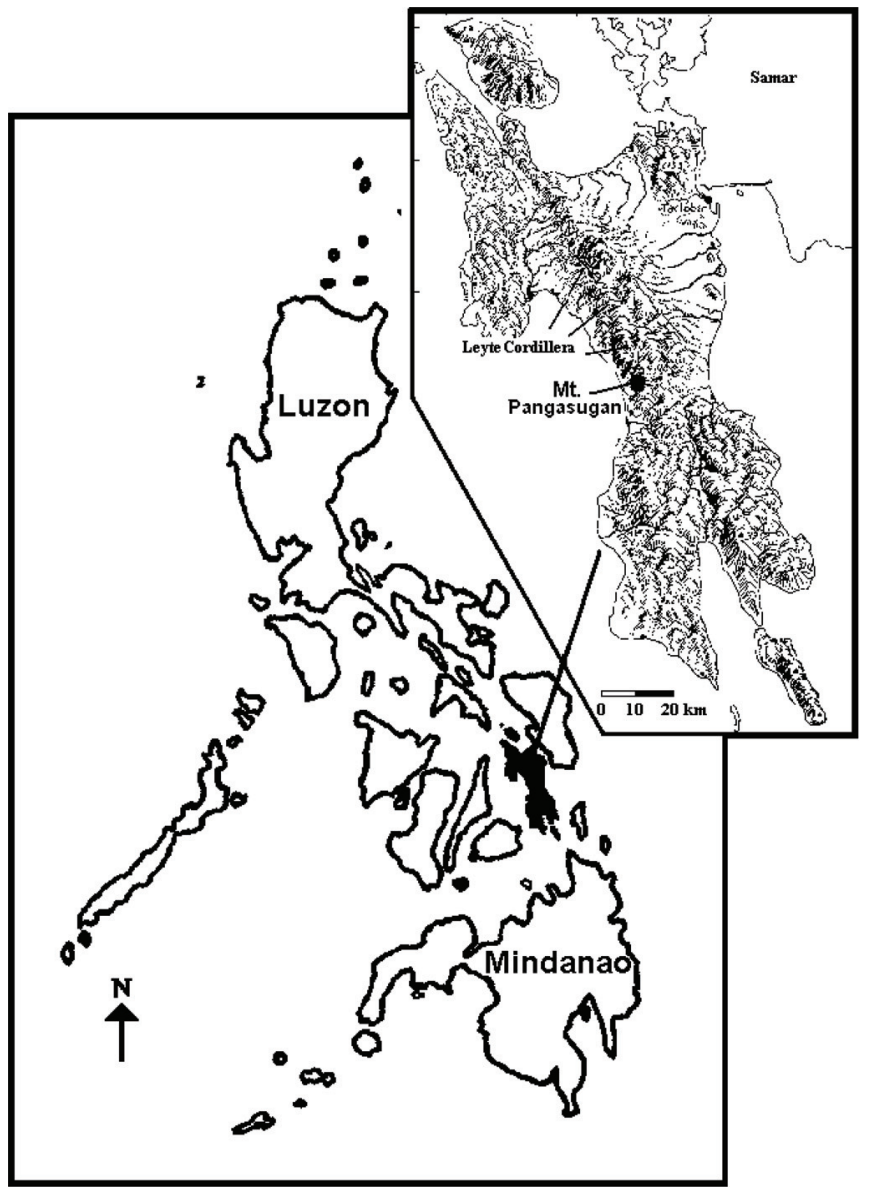

Figure 1. The Philippine archipelago and the location of Leyte.

\section{LOCATION AND ENVIRONMENTAL FACTORS}

The island of Leyte belongs to the Eastern Visayas and is the eighth largest island of the Philippine archipelago (Fig. 1). It is located between $9^{\circ} 55^{\prime}$ and $11^{\circ} 48^{\prime}$ northern latitude and $124^{\circ} 17^{\prime}$ to $125^{\circ} 18^{\prime}$ eastern longitude. Its characteristic feature is the Leyte Cordillera, a part of the Philippine fault line, which shows the typical rugged relief of young volcanic areas. Parent materials for soil formation are andesitic, basaltic and dacitic flows and breccia [3]. Soils under old growth forest at c. $500 \mathrm{~m}$ a.s.l. in the western foothills of Mt. Pangasugan have been identified as Andosols [22]. Due to its rugged relief with forested slopes of c. $30^{\circ}$ to sometimes more than $60^{\circ}$ and a high clay content of the soils, the area is prone to landslides.

The local climate as analysed from data from the weather station of the Philippine Athmospheric, Geophysical and Astronomical Services Administration (PAGASA, $7 \mathrm{~m}$ a.s.l.) on the campus of the Leyte State University (LSU) shows an average annual precipitation of $2586 \mathrm{~mm}$ [12]. The wettest months are November to January with monthly averages of c. $290 \mathrm{~mm}$. The driest months are March to May with average monthly rainfall amounts between 95.4 to $132.9 \mathrm{~mm}$. Annual as well as monthly variability is high. Although the average values are still within the range for evergreen rain forests as given by Walsh [21], drought periods occur, especially during El Niño Southern Oscillation events [12]. While seasonal rainfall patterns can be assumed to be similar for the lowlands and the mountain range, it is likely that the precipitation in the vicinity of Mt. Pangasugan's summit and its slopes is higher than the values measured at the PAGASA station due to orographic rains. Another important environmental factor affecting the vegetation is the occurrence of typhoons. Leyte lies on the southernmost typhoon tracks entering the Philippines [11]. Typhoons are responsible for excessive rainfalls, which trigger landslides and cause heavy mechanical damage in the forests through wind throws and wind breaks. A special feature of the area is a pronounced 'telescope effect' as described by van Steenis [20]: mossy forest occurs along exposed ridges and summits as low as $900 \mathrm{~m}$ a.s.l.

\section{METHODS}

This analysis is based on vegetation studies I conducted from 1996 to 1998 [12], and 2004 (unpublished). It refers to two data sets: Data set one consists of 36 plots of $100 \mathrm{~m}^{2}$ each located in the primary forest of the western foothills of Mt. Pangasugan, within the forest reserve of the Leyte State University (LSU). The plots were mainly located on one foothill locally called "Pananawan", and covered an elevational range from $200-530 \mathrm{~m}$ a.s.l. Where possible they had been arranged along a catena from ridge ( 15 plots) to lower slope ( 6 plots), through upper slope ( 6 plots) and middle slope (9 plots) (Tab. I). Nevertheless, this was often prevented by the rugged relief and the common land slides. 


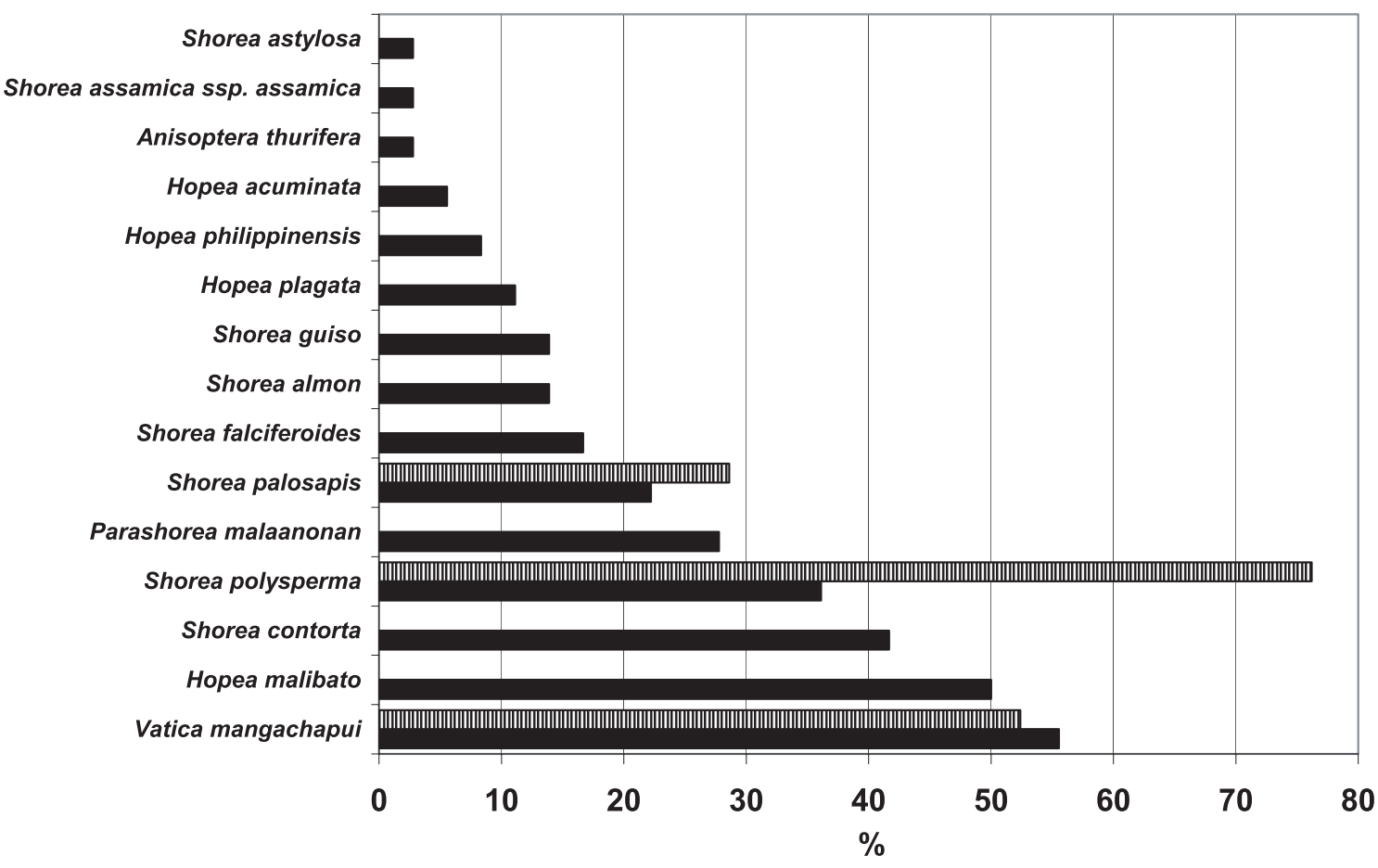

'Pananawan' plots ( $\mathrm{N}=36)$ 皿 'Happy Valley' plots ( $\mathrm{N}=21)$

Figure 2. Frequency of dipterocarp species in the two data sets from the Leyte Cordillera at Mt. Pangasugan, Leyte, Philippines.

The second data set consists of 21 plots of $100 \mathrm{~m}^{2}$ each in the southeastern outliers of Mt. Pangasugan. The area belongs to the "Community Based Forestry Management Area" (CBFMA) of the Cienda San Vicente Farmer Association and has been specified as part of an area locally called "Happy Valley". The plots were located between $647 \mathrm{~m}$ and $709 \mathrm{~m}$ a.s.l. in a homogenous old growth forest dominated by large, up to $40 \mathrm{~m}$ tall Shorea polysperma trees. The relief was very distinct compared to the Pananawan area. The locality can be described as a semicircular, gently undulating plateau sloping towards the south and being abruptly demarcated by a deeply incised river system which forms the south, west, and north boundary of the plateau. A clearcut demarcation of relief types as in the "Pananawan" plots was not possible.

Plot sampling included the assessment of abundance and coverage of all vascular plants except crown epiphytes. Plants taller than $2.5 \mathrm{~m}$ were assessed within the whole $10 \mathrm{~m} \times 10 \mathrm{~m}$ plots, and plants $>0.5$ up to $2.5 \mathrm{~m}$ tall as well as climbers in $5 \mathrm{~m} \times 5 \mathrm{~m}$ sub-plots. For this analysis plots have vertically been stratified into five height layers: T1 ("canopy layer") represented the dominant and tallest trees whose crowns were fully exposed to the sunlight. T2 ("sub-canopy layer") were those trees taller than two-thirds the height of the dominant trees (T1), but which did not (yet) reach the canopy and full exposure to sunlight. T3 ("middle layer") comprised trees taller than one-third and up to two-thirds of T1, and T4 ("lower tree layer") was defined as being taller than $2.5 \mathrm{~m}$ up to T4. U2 comprised the undergrowth $>0.5$ up to $2.5 \mathrm{~m}$ tall.

Identification of species is based on the available literature $[1,10$, $15,18]$ as well as the comparison of specimens with collections of the Philippine National Herbarium in Manila (PNH), Philippines, and the
National Herbarium of the Netherlands in Leiden (L). Voucher specimens are deposited at the Leyte State University Herbarium, Department of Biological Sciences, ViSCA, Baybay, 6521 A, Leyte, Philippines. For a more detailed description of the methodology see Langenberger [12].

The "Pananawan" plots were distributed along the whole foothill and represent a wide amplitude of environmental variability concerning elevation and relief. On the contrary, the "Happy Valley" plots were located within one homogenous old growth forest stand reflecting small scale habitat differences rather than relief types. Observations on the occurrence and distribution of dipterocarps outside the plots are considered if they provide additional information. Species frequency (Fig. 2) is based on the sampling plots data, while the elevational distribution of the species (Fig. 3) includes specimens occasionally collected outside the plots. As mean the median value has been used since the number of species occurrences was low. To calculate the box plots in Figure 3 the computer program SigmaPlot 5.0 by SPSS Inc. has been used.

For the analysis of habitat preferences (Tab. II) the data from the "Pananawan" plots and observations in the western foothills of Mt. Pangasugan have been considered using the different relief types ("ridge, upper slope, middle slope, lower slope") while the "Happy Valley" plots have been assigned to a single "habitat", which was named "undulating plateau". Since the "Happy Valley" plots represented rather homogenous habitat conditions compared to the "Pananawan" plots, the application of the relief types would have been misleading.

Additionally, the distribution of the most common species in the five height strata is given (Fig. 4) and the population structure of these species is analysed. 
m a.s.I.

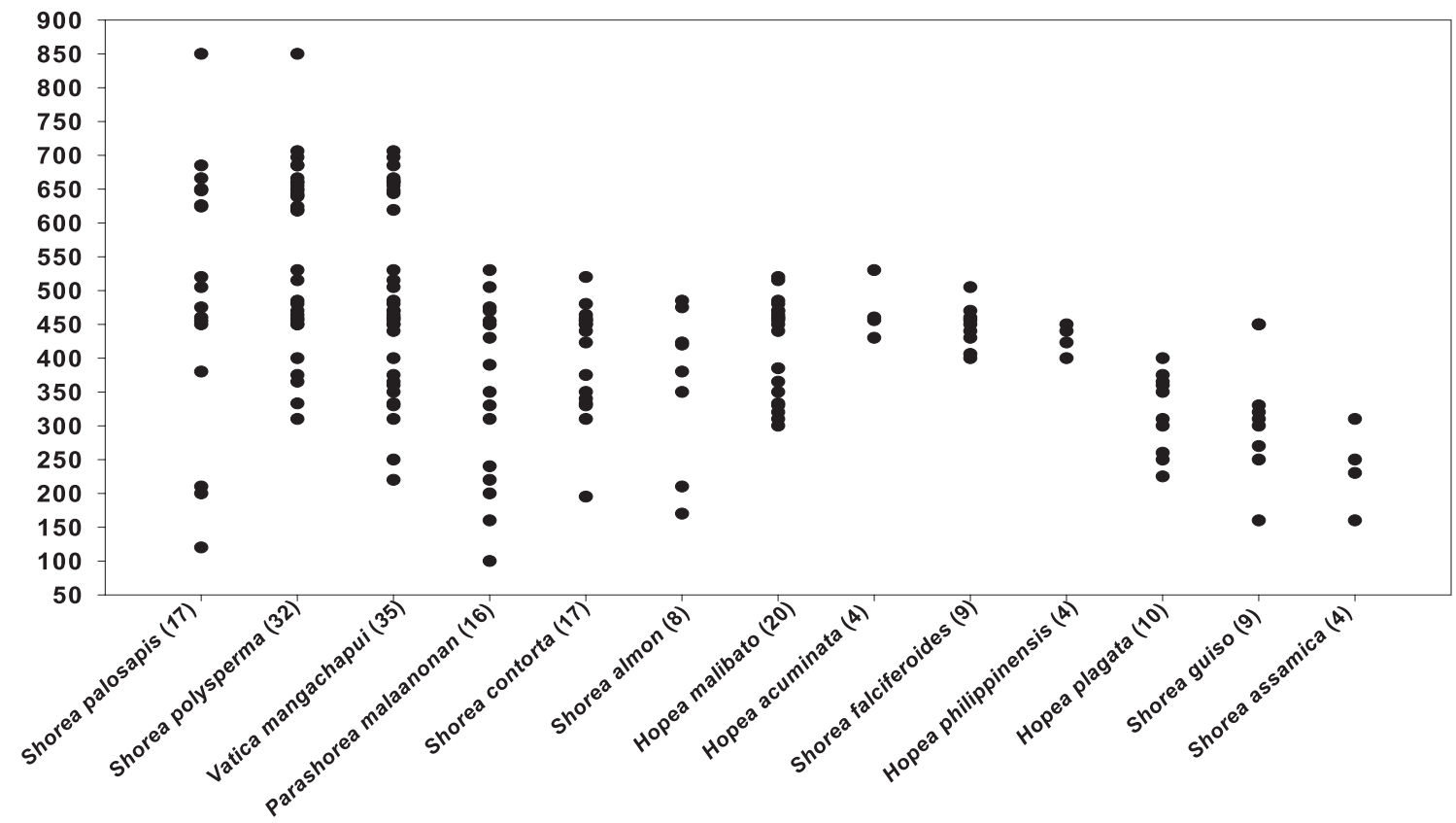

Figure 3. Observed elevational range of dipterocarp species in the Leyte Cordillera, at Mt. Pangasugan and vicinity, Leyte, Philippines. The numbers behind the species names refer to the number of observations. The number of dots not always correlates with the number of observations since one dot can represent several observations at the same elevation.
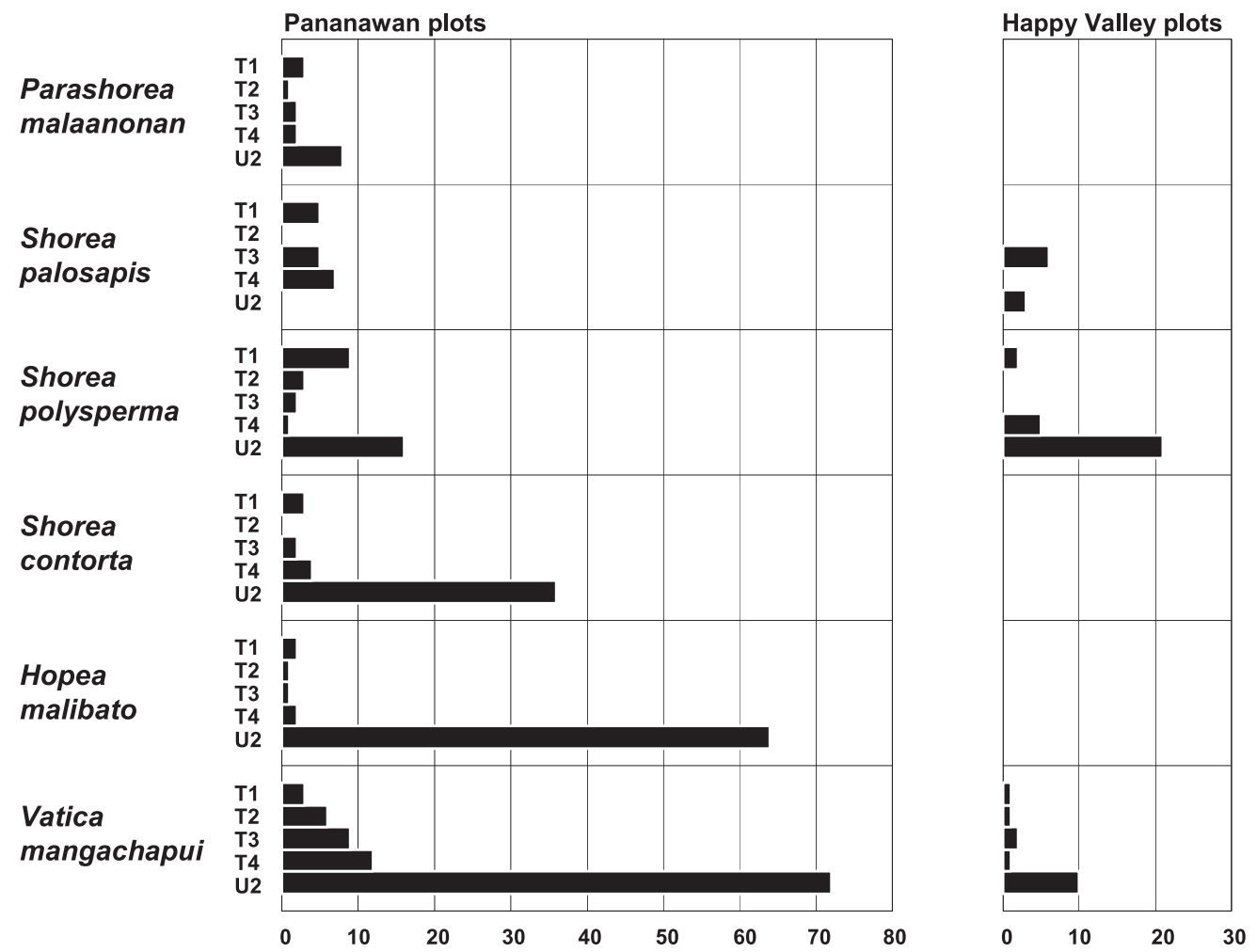

Figure 4. Representation of the six most common dipterocarp species in five height layers distinguished in the "Pananawan" and "Happy Valley" plots. Individuals encountered in 57 plots; layers T1-T4 represent $100 \mathrm{~m}^{2}$ plots, U2 subplots of $25 \mathrm{~m}^{2}$; T1: dominant tree layer, T2: $>2 / 3$ of the stand height but not yet being dominant, T3: $>1 / 3-2 / 3$ of the stand height, T4: $>2.5 \mathrm{~m}-1 / 3$ of the stand height, U2: $>0.5 \mathrm{~m}-2.5 \mathrm{~m}$. 
Table II. Occurrence patterns of the dipterocarp species encountered in the Leyte Cordillera at Mt. Pangasugan, Leyte, Philippines ${ }^{1}$.

\begin{tabular}{|c|c|c|c|c|c|c|c|c|}
\hline Species $^{2}$ & $\begin{array}{c}\text { Common official } \\
\text { name }^{3}\end{array}$ & Timber group 4 & Ridge & $\begin{array}{l}\text { Upper } \\
\text { Slope }\end{array}$ & $\begin{array}{l}\text { Middle } \\
\text { Slope }\end{array}$ & $\begin{array}{l}\text { Lower } \\
\text { Slope }\end{array}$ & $\begin{array}{l}\text { Undulating } \\
\text { Plateau }\end{array}$ & Abundance 5 \\
\hline Hopea plagata (Blco.) Vid. ${ }^{(+)}$ & Yakal-saplungan & Yakal & $* *$ & $x$ & & & & Loc. common \\
\hline Shorea polysperma (Blco.) Merr. & Tangile & $\begin{array}{l}\text { Philippine Mahogany - } \\
\text { red lauan }\end{array}$ & $* * * *$ & $*$ & $* *$ & & $* * * *$ & Common \\
\hline Vatica mangachapui Blco. & Narig & Narig & $* * * *$ & $* * * * *$ & $* *$ & $*$ & $* * *$ & Common \\
\hline Hopea malibato Foxw. ex Elm. ${ }^{(+)}$ & Yakal-kaliot & Yakal & $* * * *$ & $* * * * *$ & $* *$ & $*$ & & Loc. common \\
\hline Shorea contorta Vid. & White lauan & $\begin{array}{l}\text { Philippine Mahogany - } \\
\text { white lauan }\end{array}$ & $* *$ & $* * *$ & $* * *$ & & & Common \\
\hline Shorea falciferoides Foxw. & Yakal-yamban & Yakal & $*$ & $* * *$ & $*$ & $*$ & & Loc. common \\
\hline Hopea philippinensis Dyer & Gisok-gisok & Manggachapui & $*$ & $*$ & $*$ & $x$ & & Loc. common \\
\hline Anisoptera thurifera Foxw. ${ }^{(+)}$ & Palosapis & Palosapis & $*$ & $x$ & $x$ & & & Scattered \\
\hline Parashorea malaanonan (Blco.) Merr. & Bagtikan & $\begin{array}{l}\text { Philippine Mahogany - } \\
\text { white lauan }\end{array}$ & $*$ & & $* * *$ & * & & Common \\
\hline Shorea almon Foxw. & Almon & $\begin{array}{l}\text { Philippine Mahogany - } \\
\text { white lauan }\end{array}$ & $*$ & & $* *$ & $*$ & & Common \\
\hline Shorea guiso (Blco.) Bl. & Guijo & Guijo & $* *$ & & * & & & Loc. common \\
\hline Hopea acuminata Merr. & Manggachapui & Manggachapui & $* \mathbf{x}$ & & $*$ & & & Scattered \\
\hline Shorea palosapis (Blco.) Merr. & Mayapis & $\begin{array}{l}\text { Philippine Mahogany - } \\
\text { white lauan }\end{array}$ & & $* *$ & $* *$ & $* *$ & $* *$ & Common \\
\hline Shorea assamica Dyer & Manggasinoro & Manggasinoro & $*$ & & $x$ & $x$ & & Rare \\
\hline Shorea astylosa Foxw. ${ }^{(+)}$ & Yakal & Yakal & $*$ & & & & & Rare \\
\hline Dipterocarpus gracilis $\mathrm{B} 1 .^{(+)}$ & Panau & Apitong & $x$ & & & & & Very rare \\
\hline Shorea cf. hopeifolia (Heim) Sym. ${ }^{6(+)}$ & Kalunti & Manggasinoro & & & $x$ & & & Very rare \\
\hline Dipterocarpus validus $\mathrm{B} 1$. & Hagakhak & Apitong & & & $x$ & $x$ & & Scattered \\
\hline
\end{tabular}

${ }^{1}$ Relief types 'Ridge', 'Upper Slope', 'Middle Slope', and 'Lower Slope' refer to the occurrence in the 'Pananawan' plots, the 'Undulating Plateau' to the 'Happy Valley' plots. Frequency figures, symbolized by $*$, represent encounters within the plots of the different relief types: * $\leq 20 \%$, **21-40\%, $* * * 41-60 \%, * * * * 61-80 \%, * * * * * 81-100 \%$. Observations on the occurrence of the species outside the 'Pananawan' plots are marked with an $\mathbf{X}$.

${ }^{2}$ Species followed by $(+)$ are new descriptions for Leyte based on information given in $[1,10,13,15]$.

3 After [17]; common official names do not necessarily reflect a corresponding application of these names by local people.

4 After [16].

5 The abundance gives a qualitative assessment of the distribution pattern of the species.

${ }^{6}$ The identification is based on a juvenile plant; confirmation based on fertile specimens is necessary.

\section{RESULTS}

Based on their occurrence within the sampled plots as well as encounters during field trips, eighteen dipterocarp species could be identified at Mt. Pangasugan and its vicinities (Tab. II). The 18 species belong to the six Philippine dipterocarp genera and make up 28\% of the 65 dipterocarp species [2] known from the Philippines. Additionally, they represent all eight dipterocarp timber groups [16]. Six species were not yet described for the island of Leyte (Tab. II). One species, Shorea cf. hopeifolia, needs further confirmation based on fertile collections, since its occurrence is only described for parts of Mindanao, so far [1, 13].

The species showed distinct distribution patterns, some being common and widely distributed while others occurring only locally or even being encountered only once (Dipterocar- pus gracilis) or twice (Shorea cf. hopeifolia), thus not allowing any generalizations.

In the "Pananawan" plots, 16 out of the 18 species were represented. The most frequent species was Vatica mangachapui, which occurred in 56\% (20) of the 36 plots (Fig. 2). With decreasing frequency followed 11 species, while three species could be found in one plot (3\%), only. The additional two species, Dipterocarpus gracilis and Shorea cf. hopeifolia, have also been observed in the western foothills but outside the plots. The "Happy Valley" plots included only three dipterocarp species, Shorea polysperma, Shorea palosapis, and Vatica mangachapui. Shorea polysperma was by far the most frequent species, occurring in $76 \%$ (16 plots) of the 21 plots, followed by Vatica mangachapui with $52 \%$ (11 plots), and S. palosapis with $29 \%$ (6 plots). No other dipterocarp species was found in the "Happy Valley" area. 
The elevational range as well as habitat preferences of species are given in Figure 3 and Table II, respectively.

The highest elevation of dipterocarps observed during field work was that for Shorea palosapis and Shorea polysperma (Fig. 3). Both species could be found as medium sized trees at $850 \mathrm{~m}$ a.s.l. on an east-exposed slope of Mt. Imig, only about $50 \mathrm{~m}$ below the summit which was covered by mossy forest. The potential of both species to grow at relatively high elevation is confirmed by their presence, together with Vatica mangachapui, in the "Happy Valley" plots. The lowest elevation where dipterocarps have been found is at about $100 \mathrm{~m}$ a.s.l. (Fig. 3) along small streams. They were juveniles of Shorea palosapis and Parashorea malaanonan, which obviously had resulted from fruits washed down from higher elevations, since no mother trees could be observed nearby or on the slopes above the specimens. Nevertheless, medium sized trees of both species have been observed at similarly low elevations at other localities within the area which shows that the species are able to establish at those elevations.

The widest elevational range showed Shorea palosapis which could be encountered from the lowland (120 $\mathrm{m}$ a.s.1.) to submontane elevations ( $850 \mathrm{~m}$ a.s.l.). Compared to the other two species showing a wide elevational amplitude and reaching high up, Shorea polysperma and Vatica mangachapui, it preferred slope habitats and could not be found along ridges, while Shorea polysperma clearly preferred the ridge habitat ("Pananawan" plots) and the undulating plateau at "Happy Valley". Vatica mangachapui had its main distribution rather on the upper slope than on the ridge itself.

All other species have been encountered in the western foothills of Mt. Pangasugan, none of them higher than the highest plot there $(530 \mathrm{~m}$ a.s.1.). From those species Parashorea malaanonan and - to a lesser extend - Shorea contorta and Shorea almon also showed a comparatively wide elevational range. While Parashorea malaanonan and Shorea almon have most often been encountered on the middle slope, Shorea contorta was also common on the upper slope and along the ridge. Shorea almon mostly occurred together with Shorea palosapis.

A similar habitat preference as Vatica mangachapui could be observed with Hopea malibato, although this species was only locally common and had a much lower elevational amplitude. Like Vatica mangachapui it preferred ridge and especially upper slope habitats.

A typical low elevation species (which is not represented in Figure 3 because of its absence from plots and lack of elevational data) was Dipterocarpus validus. Mature individuals of this species could be found scattered along creeks in deforested areas between $100 \mathrm{~m}$ and $250 \mathrm{~m}$ a.s.l. All other species were too poorly represented to draw general conclusions.

The regeneration patterns of the five most frequent species is shown in Figure 4, based on the number of individuals represented in the five height layers. The smallest size class (U2) is usually best represented, although this is less pronounced in P. malaanonan and Shorea polysperma. But, only Vatica mangachapui shows a continuous decrease of individuals from the U2 layer via the different size classes towards the mature trees (T1). Shorea polysperma even shows an inverse trend, showing an increase of individuals with increasing height.

\section{DISCUSSION}

The studied part of the Leyte Cordillera harbors at least $28 \%$ of the Philippine dipterocarp species and represents all Philippine dipterocarp timber groups (Tab. II). It can provide the necessary seeds and seedlings to establish reforestations and to meet the various timber requirements of local people in the future.

Most of the species show distinct altitudinal ranges as well as marked topographic habitat preferences (Fig. 3 and Tab. II). This is not a new observation to practical foresters in the tropics as well as outside the tropics. Nevertheless, the question of tropical trees being stochastically distributed or not is still controversially discussed. Such rugged landscapes as the Leyte Cordillera in which the influential factors are much more pronounced and obvious than in more homogenous areas allow quite distinct distribution patterns that seem unlikely to be the result of a chance process.

The information on tree species-site preferences is important if such species are planned to be used in reforestation. The presented data on site-specificity are mainly based on a very small section of the Leyte Cordillera resulting in only few observations for rare or scattered species. More information is needed for the definition of their habitat preferences and elevational ranges. Additionally, more data from the eastern slopes of Mt. Pangasugan and the rest of the Leyte Cordillera is desirable.

When evaluating the species' occurrence at lower elevations in the western foothills of Mt. Pangasugan, the strong human impact must be considered. Especially some of the very rare species can be assumed to be remnants of the former forest of the coastal plain. Parashorea malaanonan, Shorea palosapis, Shorea polysperma, and Vatica mangachapui can be classified as common and widespread. The species Hopea plagata, Hopea malibato, or Hopea philippinensis are locally common. Anisoptera thurifera and Shorea assamica must be classified as scattered (Tab. II). The occurrence patterns of the above mentioned species have been similarly described by other authors [1, 23, 24]. Although those species might have lost the lower range of their habitat due to land conversion in the lowlands, they still find suited ecological niches within the studied area. For Hopea acuminata and Hopea philippinensis, which show a low frequency as well as a clustered occurrence, their real elevational potential cannot be given based on the available data. For Shorea assamica, which is also represented by few observations, it is quite safe to conclude that it prefers lower elevations since the four observations are derived from different localities.

The evaluation of those species which are scattered or rare is more difficult. Dipterocarpus validus is well known for its occurrence on flood plains and along rivers at low elevations $[18,23,24]$. Its occurrence in the lower foothills of Mt. Pangasugan clearly represents fragments of its former distribution, and it can be safely concluded that the species lost most of its potential habitat. It is unusual that single mature forest trees can still be found in an otherwise deforested landscape. One explanation might be that these trees, which grow along the river banks or on the banks of small ravines which are usually not cleared for shifting cultivation, had not reached a harvestable size when the cutting of trees was not yet restricted and controlled. 
Nowadays, a logging ban prohibits the cutting of trees, and it is difficult to cut a tree unobserved in the highly populated and frequented lowlands. Much more critical is the situation of Dipterocarpus gracilis. Although it can be assumed that besides the single juvenile specimen encountered some mature trees might be left, this species may be classified as locally extremely rare and vulnerable. But to what extent its rarity reflects human impact or is natural is again difficult to evaluate. Ashton [1] describes the species as very widespread, and even gregarious under seasonal conditions, while it gets rare in ever wet areas. This shows how difficult a qualitative evaluation of species occurrence is without having sound historical data.

The observation of only three dipterocarp species in the "Happy Valley" area is remarkable, especially since even around the field camp, which was located at the foot of the plateau (500 $\mathrm{m}$ a.s.1.), along a small creek, no additional dipterocarp species has been encountered. It confirms the assumption that many of the species so far only observed on the western side of the mountain range are actually typical species of the coastal plains which found their refuge in the rugged western foothills of Mt. Pangasugan. The dominant role of Shorea polysperma in the "Happy Valley" plots (649-709 m a.s.1.) has been mentioned above. Vatica mangachapui was also a common feature represented by mature individuals. On the contrary, Shorea palosapis, which was represented by tall individuals near the field camp and on the lower slopes along the river was only poorly represented in the plots, and the few individuals found there represented small to medium sized trees. This supports the impression that the species strictly prefers very humid conditions, and that, on the other hand, the stand where the "Happy Valley" plots have been sampled represents comparatively dry conditions.

It can be concluded that for those species which prefer medium to higher elevations or show a wide range of elevational occurrence the studied area is an important stronghold for the conservation of their populations and their genetic diversity. This is the case with Parashorea malaanonan, Shorea contorta, Shorea palosapis, Shorea polysperma, and Vatica mangachapui. For Shorea polysperma it might even be concluded that it still occupies its full potential range. For those species which are scattered or rare the area also acts as a refuge. But their populations are naturally more vulnerable concerning the loss of individuals due to illegal logging or shifting cultivation, simply because of their low abundance.

Although much more specific and comprehensive data are desirable to define habitat preferences of the local dipterocarp species the above analysis provides important baseline information. Even though it might be possible to plant species successfully in other habitats, when competition is suppressed, the question arises if this would be sustainable on the long run. Considering the dynamics of tropical rain forest environments this can be doubted. Unfortunately, detailed documentation and analysis of reforestation trials with native species are hardly available - if they exist at all. Usually, in national statistics only the area which has been planted is listed. If planting has been successful and sustainable after five or ten years can rarely be found. Systematic scientific trials to test the site specific suitability of species or even provenances for reforestation or land rehabilitation as they have been conducted e.g. in Europe for decades seem illusionary given the economic situation of most tropical rain forest countries. They are even not practical considering the urgent needs for reforestation and land rehabilitation in so many areas of the tropics. Therefore, if native species are to be promoted, the only practical way to reduce the risks of failure due to the selection of unsuited habitats is to stick to observations on the natural occurrence of the species.

Acknowledgements: The vegetation study in the western foothills of Mt. Pangasugan has been conducted in the framework of the "ViSCAgtz Applied Tropical Ecology Program" (PN 95.2290.5-001.00). The additional research in the "Happy Valley" area has been made possible by a grant of the A.F.W. Schimper Foundation, Stuttgart - Hohenheim, Germany, whom I owe special thanks. I am very grateful to the Cienda San Vicente Farmer Association as well as the Leyte State University (LSU), Leyte, Philippines, for their cooperation and support. Thanks are also due to Nina Ingle and the two anonymous reviewers for their helpful comments.

\section{REFERENCES}

[1] Ashton P.S., Dipterocarpaceae, in: van Steenis C.G.G.J. (Ed.), Flora Malesiana Series I, Vol. 9 (2), Martinus Nijhoff Publishers, The Hague, The Netherlands, 1982, pp. 237-552.

[2] Ashton P.S., Philippine phytogeography, Asia Life Sci. 2 (1993) 1-8.

[3] Asio V., Characteristics, Weathering, Formation and Degradation of Soils from Volcanic Rocks in Leyte, Philippines, Hohenheimer Bodenkundliche Hefte 33, Univ. Hohenheim, Institut für Bodenkunde und Standortslehre, Stuttgart, 1996.

[4] Butterfield R.P., Fisher R.F., Untapped potential: native species for reforestation, J. For. 92 (1994) 37-40.

[5] Dargantes B.B., Koch W., Case studies on the occupation and cultivation of the forest lands of Leyte, Philippines, Ann. Trop. Res. 16 (1994) 13-29.

[6] DENR, Philippine atlas, Department of Environment and Natural Resources (DENR), Quezon City, The Philippines, 1998.

[7] Dias C.P., ERDB's research and development (R\&D) experience(s) in reforestation with Philippine native tree species, in: Margraf J., Göltenboth F., Milan P.P. (Eds.), Proceedings on the International Conference on Reforestation with Philippine Species - for biodiversity protection and economic progress, 3-6 March 1997, MacArthur Beach Resort, Palo, Leyte, Philippines, 1997, pp. 156-174.

[8] Elliot S., Blakesley D., Anusarnsunthorn V. (Eds.), Forests for the future: growing and planting native trees for restoring forest ecosystems, Forest Restoration Research Unit, Biology Department, Faculty of Science, Chiang Mai University, Chiang Mai 50200, Thailand, 1998.

[9] ESSC, Decline of the Philippine Forest, Environmental Science for Social Change, Inc., The Bookmark, Inc., Makati City, The Philippines, 1999.

[10] Guzman E.D. de, Umali R.M., Sotalbo E.D., Guide to Philippine Flora and Fauna, Vol. 3: Dipterocarps, Non-Dipterocarps, Natural Resources Management Center, Ministry of Natural Resources \& University of the Philippines, 1986.

[11] Kintanar R.L., Climate of the Philippines, PAGASA, Quezon City, Philippines, 1984.

[12] Langenberger G., Diversität, Struktur und Reliefabhängigkeit der Vegetation in einem Tieflandregenwald der Insel Leyte, Philippinen, Dissertation, Institut für Pflanzenproduktion und Agrarökologie der Tropen und Subtropen (380), Universität Hohenheim, 2003.

[13] Merrill E.D., An Enumeration of Philippine Flowering Plants, Vol. I-IV, The Government of the Philippine Islands, Department of 
Agriculture and Natural Resources, Bureau of Science, Manila, 1923-1926.

[14] Milan P.P., Margraf J., Rainforestation farming, an alternative to conventional concepts, Proc. Sustainable Alternative Livelihood Project Symposium, Quezon City, Philippines, November 10-11, 1994.

[15] Newman M.F., Burgess P.F., Whitmore T.C., Manuals of Dipterocarps for Foresters: Philippines, Center for International Forestry Research, Jakarta, Indonesia, 1996.

[16] PCARR, The Philippines Recommends for Dipterocarps: I. Lumber, Forest Products Research and Industries Development Commission (FORPRIDECOM), NSDB, College, Laguna, 1977.

[17] Salvosa F.M., Lexicon of Philippine Trees, Forest Products Research Institute, College, Laguna, Philippines, 1963.

[18] Seeber G., Weidelt H.-J., Banaag V.S., Dendrological characters of important forest trees from eastern Mindanao, 2nd ed., Deutsche Gesellschaft für Technische Zusammenarbeit (GTZ) GmbH, DagHammarskjöld-Weg 1+2, Postfach 5180, D 6236 Eschborn 1, 1985.
[19] Soerianegara I., Lemmens R.H.M.J., Plant Resources of South-East Asia, Timber tree: Major commercial timbers, Prosea, Bogor, Indonesia, 1994.

[20] Steenis C.G.G.J. van, The mountain flora of Java, Brill, Leiden, The Netherlands, 1972.

[21] Walsh R.P.D., Climate, in: Richards P.W. (Ed.), The Tropical Rain Forest, Cambridge University Press, 1996, pp. 159-205.

[22] Zikeli S., Nutrient status and nutrient cycles of the tropical rainforest, Mt. Pangasugan, Leyte, Philippines, Diploma thesis at the Martin Luther University Halle - Wittenberg, Landwirtschaftliche Fakultät, Inst. für Bodenkunde und Pflanzenernährung, 1998.

[23] Weidelt H.J., Banaag V.S., Aspects of Management and Silviculture of Philippine Dipterocarp Forests, GTZ Publication No. 132, TZ Verlagsgesellschaft mbH, 6101 Rossdorf 1, Germany, 1982.

[24] Whitford H.N., The Forests of the Philippines, Part II: the Principal Forest Trees, Bureau of Forestry Bulletin No. 10, Manila, Bureau of Printing, 1911. 